\title{
Quality of life after coronary artery bypass graft surgery - results of cardiac rehabilitation programme
}

\author{
José Manuel Afonso Moreiraa,** Eugénia Nunes Grilo² \\ ${ }^{1}$ Portuguese Institute of Oncology - Francisco Gentil, Lisbon, Portugal \\ ${ }^{2}$ Polytechnic Institute of Castelo Branco, São João de Deus School of Nursing, Dr Lopes Dias School of Health University of Évora, Castelo Branco, Portugal
}

\begin{abstract}
Accountability, involvement, empowerment of the patients and families/ caregiver, as well as the incentive for health behaviors based on physical exercise and healthy living habits with the support of health professionals, are fundamental in meeting the demands of the current society. The main objective of this report is to describe the process of developing skills in rehabilitation nursing that was possible in the context of the final stage in which an intervention program in the area of cardiac rehabilitation was designed, implemented and evaluated. In this quantitative study with exploratory characteristics, it was used the collection of observable and quantifiable data, from patients submitted to coronary artery bypass grafting. During the study, the Kolmogorov-Smirnov test was applied - being verified the normal distribution - and Student t-test, which aimed at comparing outcomes at the beginning and end of the program. When 6-min walk test was applied, there was an optimi-
\end{abstract}

\section{INTRODUCTION}

Cardiovascular diseases are the order of the day and are currently recognized as preponderant in the health policies of more developed societies (Kotseva et al., 2016). Data from the Organization for Economic Co-operation and Development of 2013 for the European Society of Cardiology, hold that these diseases are the leading cause of death in the European Union with $45 \%$ of all deaths ( 4 million/yr), resulting in $19 \%$ in men and $20 \%$ in women (Townsend et al., 2015).

In the world, diseases of the circulatory system lead the mortality rate, which allows to verify the need to implement measures aimed at prevention (Herdy et al., 2014; Sandesara et al., 2015; Thomas et al., 2018). Risk factors and comorbidities inherent to cardiac pathology play an important role in the onset and devel- zation of functional capacity $(P=0.05)$, can be proved by the fact that all the patients had statistically significant improvements in the time-walk relationship. Furthermore, the quality of life in those who participated in the program was moderate in the preoperative period with $53.09 \%$, and at the end a significant improvement was observed with $75.02 \%$. Cardiac rehabilitation is fundamental in the patient submitted to coronary artery bypass grafting, taking into account the educational, physical exercise, and quality of life dimensions. Given the prevalence of risk factors associated with cardiovascular disease, differentiated intervention in rehabilitation nursing becomes essential in the training of patients for self-care.

Keywords: Cardiac rehabilitation, Quality of life, Rehabilitation nursing, Exercise
${ }^{*}$ Corresponding author: José Manuel Afonso Moreira

(iD) https://orcid.org/0000-0003-0059-768X

Portuguese Institute of Oncology - Francisco Gentil, Street Professor Lima Basto 1099-023, Lisbon, Portugal

E-mail: jafonsomoreira@gmail.com

Received: August 9, 2019 / Accepted: September 4, 2019 opment of this disease (Townsend et al., 2015). Approximately $75 \%$ to $90 \%$ of the incidence of coronary artery disease in a given population is due to inadequate eating habits, physical inactivity, and smoking habits (Sandesara et al., 2015).

Therefore, it is urgent to implement programs in this clinical area due to their effectiveness in the physical, social and mental components of the patients who participate in them (Griffo et al., 2013; Pinto et al., 2019). Nurses, because of their proximity, have a strategic position to guide and regularly verify the motivation and the operationalization of the plans delineated with the user, and that in most cases, promote changes in lifestyles providing a higher quality of life (Mares et al., 2018). Having the need to perceive the real health condition of the populations, it is important to monitor the indicator that demonstrates the current health condition, that is, the quality of life. In the last years, there has 
been a significant evolution in the assessment of quality of life in patients with coronary heart disease, and the same is not true in those who undergo coronary artery bypass grafting.

As a result of an increasing number of cardiac surgery, a greater scientific investment is essential at this stage in which the patient is hospitalized (Winkelmann et al., 2015). In the coronary artery bypass grafting user, functional capacity optimization is largely due to respiratory exercises prior to hospitalization, being essential after the surgery an early and progressive mobilization in order to reduce the days of hospitalization, respiratory complications and arrhythmias (Herdy et al., 2014).

Before surgery, easy fatigue caused by heart failure and subsequently the inherent consequences of it (pain and reduction of mobility reduced by sternotomy), lead to a conditioning in the capacity that the patients have in the various daily living activities. The action of the rehabilitation nurse specialist to eliminate the self-care deficit in the user submitted to coronary artery bypass grafting begins in the preoperative period with the nursing consultation, gradually approaching the management of the therapeutic regimen, surgical wound care, measures for the control of pain, physical activity, nutrition, sexual activity, and healthy lifestyle habits (Mares et al., 2018). The promotion of autonomy should be taken into account in preparing for discharge, in the transition from the inpatient to the outpatient regime, so that the patient can maintain life, health and well-being (Borzou et al., 2018; Mares et al., 2018).

In the postoperative period, according to the American College of Cardiology/American Heart Association guidelines, the rehabilitation nurse specialist intervention in phase I of the cardiac rehabilitation is based on the execution and training of respiratory rehabilitation techniques (highlighting the exercises of thoracic expansion, active cycle of respiratory techniques, assisted cough, "huffing"), in caring for the sternotomy, in performing dynamic exercises based on individual assessment, and an educational plan appropriate to the new health situation (Achttien et al., 2013; Thomas et al., 2018).

Moreover, in the postoperative period, but already in phase II of cardiac rehabilitation, the evaluation of the patient and the respective recovery plan should be performed by a member of the multidisciplinary team (Achttien et al., 2013). However, this evaluation should be conducted by nurses who are in a privileged position in the health units, due to their relationship with people, and therefore play a central role in health promotion and disease prevention (Mares et al., 2018).

\section{MATERIALS AND METHODS}

Being the research of the utmost importance to improve the knowledge and attending to the problematics of this work (the benefits of specialized rehabilitation nursing care to users submitted to coronary artery bypass grafting), it is verified that there is no recent evidence, so it is justified to conduct a study of exploratory characteristics.

This is a quantitative study because: a systematic process of collecting observable and quantifiable data was used; the results obtained from the users were quantified; there is objectivity in the whole process; knowledge development and validation was verified. It can be seen that the study is quantitative in nature due to the facts of: using a systematic process of collecting observable and quantifiable data; the results obtained from users are quantified; objectivity in the whole process; verify the development and validation of knowledge. The population were all patients of the cardiothoracic surgery service of a Portugal hospital unit, in the various valences that constitute it: outpatient consultation, operating room, intensive care unit and ward. The sample consisted of 11 proposed users submitted to coronary artery bypass grafting, being a nonprobabilistic and convenience sample. Of the 11 coronary artery bypass grafting users, five were female and six males, aged between 54 and 77 years.

In accordance with the American Heart Association criteria for exercise and the postevent safety clinical risk assessment by American Association of Cardiovascular and Pulmonary Rehabilitation, the inclusion criteria of the users were: proposed and/or submitted to coronary artery bypass grafting over 18 years old; with low or moderate risk of cardiac episode; class B for the participation and supervision of physical exercise; with a left ventricular ejection fraction greater than $40 \%$; there are no signs and/or symptoms after coronary artery bypass grafting; Patients with stable chronic heart failure; controlled arterial hypertension, no arrhythmias, no motor or psychic changes, and after acceptance of informed consent.

In accordance with the American College of Sports Medicine guidelines, the following assessment instruments were used: 6-min walk test; modified Borg scale; hemodynamic values: blood pressure, heart rate and pain (numerical scale); and Short Form Health Survey 36 (SF-36V2) (Borzou et al., 2018; Hillis et al., 2012; Riebe et al., 2015; Sadeghi et al., 2015; Winkelmann et al., 2015). The 6-min walk test during hospitalization in patients undergoing coronary artery bypass grafting allows to evaluate the submaximal effort, the capacity to perform the daily living activi- 
ties, as well as the objective assessment of symptoms and functional capacity for exercise (Sawatzky et al., 2014). This was applied in the ward corridor, which is characterized by being flat and wide, with a length of $50 \mathrm{~m}$.

The patient was informed that he would walk the corridor according to his abilities for $6 \mathrm{~min}$, and that he could stop for a rest whenever necessary. Vital signs were evaluated and recorded during the test, at the initial, intermediate and final periods, as well as the distance covered.

In turn, the modified Borg scale for the assessment of the subjective perception of effort allowed to determine in real time a safety limit for training throughout the program designed (Amorim et al., 2019). Being a scale that allows to evaluate the intensity of the sensation of effort, the user was asked during the sessions of the program, to indicate the sensation of perceived effort at a certain moment of the exercise. Vital parameters, such as blood pressure, heart rate, and pain are clinical indicators of the patient's physiological condition, so monitoring is essential (Piepoli et al., 2016; Sadeghi et al., 2015; Winkelmann et al., 2015). Effectively, altered blood pressure and heart rate condition and are conditioned by ventilation, therefore, tachycardia may appear during the exercise (Winkelmann et al., 2015). Exercise in hospitalized patients depends largely on personal health history and clinical situation, so the subjective perception of effort is complemented by heart rate in the evaluation of exercise intensity (Piepoli et al., 2016; Riebe et al., 2015). Pain was also monitored throughout the sessions, as its assessment through exercise programs provides useful clinical information (namely chest pain, burning sensation, discomfort, leg pain) (Piepoli et al., 2016).

The assessment of the health-related quality of life of patients undergoing coronary artery bypass grafting was obtained by applying the SF-36V2 questionnaires, as it is multidimensional based on two core components, physical and mental health. These two components are subdivided into eight dimensions, namely the physical summary measure comprising the dimensions of physical function, physical performance, pain, general health and the mental summary measure that include vitality, social function, emotional performance, and mental health dimensions (Diab et al., 2018).

Statistical analysis of the data was fulfilled using the statistical package for social sciences program. For this analysis, and considering the variables under study, measures of central tendency (mean), dispersion measures (standard deviation) and measures of the distribution of the sample elements (measures of asymmetry and flatness) were used. For the inferential analysis, evaluating the response to the cardiac rehabilitation program, the outcomes were compared both at the beginning and end of the program.

When applying the Kolmogorov-Smirnov test (nonparametric test) based on the hypothesis of the influence of the delineated cardiac rehabilitation program, it was found that the variables follow a normal distribution, so proceeded to the parametric statistics. Was used Student $t$-test for independent samples of two independent measures, assuming 0.05 as a critical value of significance for the statistical test results, rejecting the existence of associations/ differences when the probability of error exceeds this value.

After being submitted to the Ethics Committee the University of Évora and next approval of the intervention project by the Scientific Council of Nursing São João de Deus - University of Évora and by those responsible for the cardiothoracic surgery specialty of that hospital unit, informed consent in writing was signed by each of the program participants.

Respect for and confidentiality of personal information was maintained, preserving the anonymity of participants and their rights regarding their privacy. The SF-36V2 questionnaires were completed by the participants themselves, in private, during hospitalization. After discharge, these were filled in by the study author during telephone contact, in a private room of that hospital unit.

\section{Objective}

It is important to define what is intended to be achieved in terms of research based on rehabilitation nursing interventions for coronary artery bypass grafting users, based on the following questions: What is the influence of a rehabilitation nursing care program on the quality of life of coronary artery bypass grafting patients? What are the benefits of early action, rehabilitation nurse specialist after coronary artery bypass grafting, in phase I and in the safe transition to phase II cardiac rehabilitation?

In exploratory studies, the specific objectives should be the strategies to reach the general objective of the work. The main goal was to understand and demonstrate the importance of rehabilitation nursing care in improving the quality of life of coronary artery bypass grafting patients, based on an intervention project with a cardiac rehabilitation program. Specific aims are: Promoting improvement in the quality of healthcare provided by rehabilitation nurse specialist, using evidence-based practice and ethical-deontological principles; Evaluate the impact of the cardiac rehabilitation program, based on physical exercise and health-related quality of life, in phase I (hospitalization) and phase II (after discharge); Compare the results obtained with the results of other studies. 
Table 1. Program during hospitalization

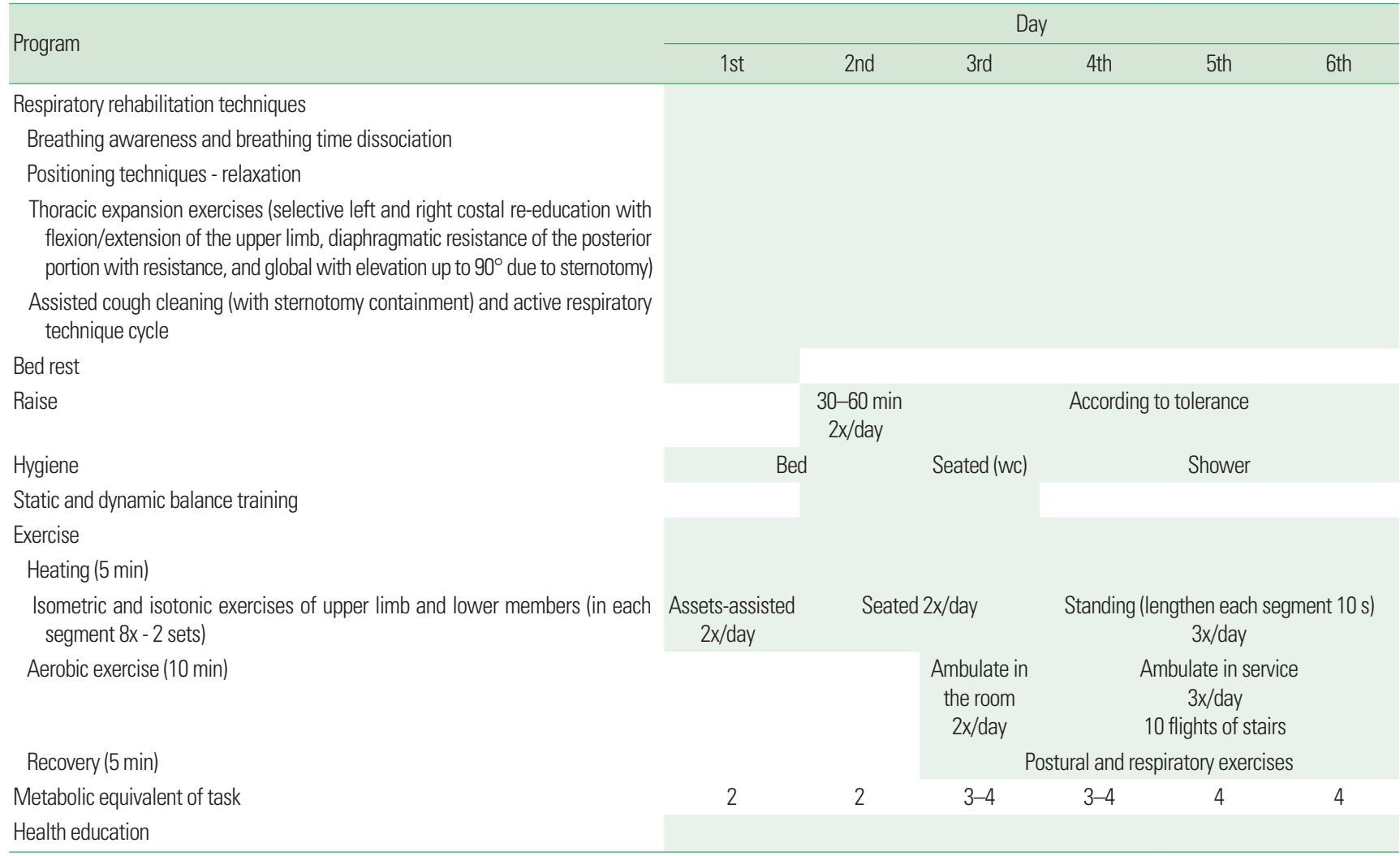

\section{Programme}

The elaboration of the program, based on the adequate physical exercise to the abilities of each patient submitted to coronary artery bypass grafting (Table 1), is fundamental in the reduction of postoperative complications and essential in the clinical discharge (Table 2), since it allows the development of confidence and reduction of the impact caused by anxiety and depression (Winkelmann et al., 2015).

\section{RESULTS}

The intervention project took place during the period of 19 September and ended on 24 November 2017, having integrated the project 11 users, with an average of $5.82( \pm 0.87)$ days of hospitalization. There were no significant differences regarding the ages and days of hospitalization.

Regarding the risk factors for cardiovascular disease identified in the patients of this study: all had arterial hypertension, eight patients had heart failure, only four with type II diabetes mellitus, eight with dyslipidemia, three with smoking habits, already ceased, eight with sedentary behavior, and five obese. Of the 11
Table 2. Program after hospital discharge

\begin{tabular}{|c|c|c|c|c|}
\hline \multirow{2}{*}{ Exercise-3x/wk } & \multicolumn{4}{|c|}{ Week } \\
\hline & $1 \mathrm{st}$ & 2nd & $3 r d$ & 4th \\
\hline $\begin{array}{l}\text { Heating (articular mobilizations+ } \\
\text { breathing exercises) }\end{array}$ & & \multicolumn{3}{|c|}{$\begin{array}{c}15-20 \mathrm{~min} \\
1 \text { set of } 8 \text { to } 10 \text { repetitions }\end{array}$} \\
\hline Aerobic exercise (hiking) & Internship & \multicolumn{3}{|c|}{$\begin{array}{l}\text { 20-min walk on flat floor with } \\
\text { normal step (1.6 to } 4 \mathrm{~km} / \mathrm{hr} \text { ) }\end{array}$} \\
\hline $\begin{array}{l}\text { Recovery (muscle segment } \\
\text { stretches) }\end{array}$ & & \multicolumn{3}{|c|}{$\begin{array}{c}15-20 \text { min } \\
1 \text { set of } 8 \text { to } 10 \text { repetitions }\end{array}$} \\
\hline
\end{tabular}

users studied, all had at least two associated risk factors.

In addition to risk factors, the other variables studied were: functional capacity translated into the distance traveled by patients during hospitalization; variation in hemodynamic values at rest as being blood pressure and heart rate (during exercise sessions performed during phase I); and the quality of life of the user after coronary artery bypass grafting.

After the beginning of the program in phase I, and after the application of the 6-min walk test, only six patients performed two postoperative evaluations of this test. The minimum distance traveled by the first six users (D1) was $125 \mathrm{~m}$ and the maximum 
Table 3. Distances traveled by patients in each phase I session

\begin{tabular}{lcc}
\hline Patient & D1 (m) & D2 $(\mathrm{m})$ \\
\hline A & 200 & 300 \\
B & 225 & 325 \\
C & 200 & 200 \\
D & 150 & 200 \\
E & 175 & 200 \\
F & 125 & 175 \\
Mean \pm SD & $179.17 \pm 36.79$ & $233.33 \pm 62.58$
\end{tabular}

D1, distance traveled for the first time after surgery; D2, distance traveled on the last day of the program in phase I; SD, standard deviation.

Table 4. Average values of patients' hemodynamic situation in each phase I session

\begin{tabular}{lc}
\hline Variable & Mean \pm SD \\
\hline HR1 (bpm) & $89.75 \pm 10.53$ \\
HR2 (bpm) & $83.13 \pm 13.37$ \\
BPs1 (mmHg) & $115 \pm 10.32$ \\
BPs2 (mmHg) & $114.25 \pm 19.85$ \\
BPd1 (mmHg) & $67.63 \pm 11.49$ \\
BPd2 (mmHg) & $64.5 \pm 8.89$ \\
\hline
\end{tabular}

$H R 1$, resting heart rate in the first session of the program (phase I); HR2, resting heart rate in the last session of the program (phase I); BPs1, minimum systolic blood pressure at rest in the first session of the program (phase I); BPs2, minimum systolic blood pressure at rest in the last session of the program (phase I); BPd1, minimum diastolic blood pressure at rest in the first session of the program (phase 1); BPd2, minimum diastolic blood pressure at rest in the last session of the program (phase I).

$175 \mathrm{~m}$, distance of $179.17 \mathrm{~m}$ and a standard deviation of $36.79 \mathrm{~m}$. The distance traveled by the six users in the last assessment of the 6-min walk test in phase I (D2) was $175 \mathrm{~m}$ minimum and $325 \mathrm{~m}$ the maximum, with an average of $233.33 \mathrm{~m}$ and a standard deviation of $62.58 \mathrm{~m}$ (Table 3).

After analyzing these data, it is possible verify that all users who applied the 6-min walk test had statistically significant improvements in the time-walking relationship, with an optimization of their functional capacity $(P=0.05)$. After applying the $t$-test for independent samples, it revealed that the difference in the distances covered was significant at a confidence level of $95 \%$.

Besides functional capacity, the maximum exercise capacity was presented, being directly related to exercise intensity (Sadeghi et al., 2015). In our study, the modified Borg scale was applied to evaluate the subjective perception of effort, as well as the metabolic equivalent task (met's) for the demonstration of energy expenditure. According to the European Society of Cardiology guidelines, and most of these users being under beta-blockers, exercise should meet symptoms and heart rate during the program and,

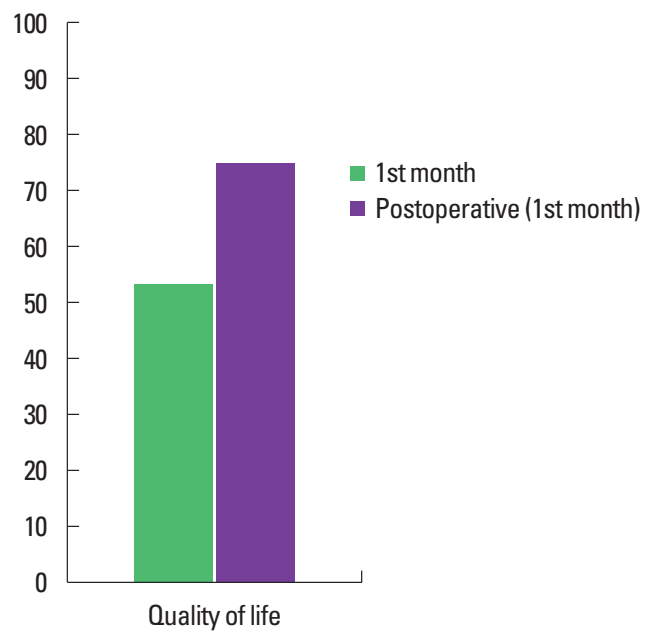

Fig. 1. Quality of life of patients before and after coronary artery bypass graft surgery.

therefore, exercise intensity should be based on the maximum capacity translated into met's and/r value on the modified Borg scale (Piepoli et al., 2016). All patients, who participated in the program, performed activities and exercises up to 4 met's intensity.

Regarding hemodynamic values throughout phase I, there was a decrease when evaluated at the beginning of all sessions of phase I (Table 4). However, after applying the Student $t$-test it was found that for independent samples the differences heart rate $(P=0.15)$ and systolic blood pressure $(P=0.47)$ and diastolic blood pressure $(P=0.29)$ at rest were not significant during the program.

Concerning the quality of life, its assessment was considered in the coronary artery bypass grafting user, following a rehabilitation nursing program based on teaching and supervised exercise (phase I of cardiac rehabilitation). In the preoperative period, overall quality of life remained moderate, concretely, $53.09 \%$ on a scale of $0 \%$ to $100 \%$, and in the first month after surgery (phase II of cardiac rehabilitation) a significant improvement with $75.02 \%$, shown in Fig. 1.

Given the eight domains, and after applying the SF-36V2 questionnaires, there was a percentage increase in all, in the first month after surgery (Diab et al., 2018). However, after application of the $t$-test at a confidence level of $95 \%$, it was more significant in the physical function $(P=0.002)$, physical performance $(P=0.01)$, general health $(P=0.05)$, social function $(P=0.04)$, and emotional performance $(P=0.002)$ domains. In the pain $(P=0.09)$, vitality $(P=0.07)$, and mental health $(P=0.45)$ domains, there was an increase, however, it was not statistically significant (Table 5). 
Table 5. The eight dimensions of quality of life before and after coronary artery bypass grafting (0\% to $100 \%$ scale)

\begin{tabular}{|c|c|c|c|c|c|c|c|c|}
\hline & \multicolumn{4}{|c|}{ MSF } & \multicolumn{4}{|c|}{ MSM } \\
\hline & $\mathrm{FF}$ & DF & $\mathrm{DR}$ & SG & SM & FS & $\mathrm{DE}$ & VT \\
\hline Preoperative (\%) & 46.82 & 56.82 & 49.54 & 52.27 & 82.27 & 47.73 & 50 & 61.93 \\
\hline Postoperative (1st month) (\%) & 79.09 & 72.16 & 74.55 & 73.64 & 83.18 & 69.31 & 71.97 & 72.16 \\
\hline t-test & 0.002 & 0.01 & 0.09 & 0.05 & 0.45 & 0.04 & 0.002 & 0.07 \\
\hline
\end{tabular}

FF, physical function; DF, physical performance; DR, pain; SG, general health; VT, vitality; FS, social function; DE, emotional performance; SM, mental health; MSF, physical summary measure; MSM, mental summary measure.

\section{DISCUSSION}

Exercise-based cardiac rehabilitation programs in patients with coronary heart disease reinforce the importance of aerobic exercise in reducing factors such as their mortality rate, namely obesity, arterial hypertension, type II diabetes mellitus and dyslipidemia (Achttien et al., 2013). As the coronary artery bypass grafting inherent period is described as critical, it becomes easier to in still changes in risk factors leading to a healthier lifestyle (Griffo et al., 2013).

In a review made in 2015 , reference is made through a pyramid on the first-line strategy to prevent the cardiac event or its recurrence (Sandesara et al., 2015). They state that the change in unhealthy lifestyles (namely bad eating habits), smoking and physical inactivity leads to a decreased risk of cardiovascular disease (Sandesara et al., 2015).

The information provided through a program outlined by 2020 under the title "Life's Simple 7" underlines the influence that risk factors have on the economic and health of the American population (Benjamin et al., 2018). Tobacco consumption (actively and passively) accounted for about 7.2 million deaths in 2015 worldwide, causing over 480,000 deaths per year of Americans (Benjamin et al., 2018). It is further noted that, from 1980 to 2013, the number of overweight and/or obese adults worldwide increased from $28.8 \%$ to $36.9 \%$ in men, and from $29.8 \%$ to $38.0 \%$ in women (Benjamin et al., 2018). One in three Americans has high-density lipoproteins cholesterol levels and 94.6 million have total cholesterol values greater than $200 \mathrm{mg} / \mathrm{dL}$, and for arterial hypertension, the numbers are even more worrying because in the last ten years the actual number of deaths has increased by $37.5 \%$ (Benjamin et al., 2018).

The benefits of cardiac rehabilitation programs in optimizing functional capacity were also described in a cross-sectional study conducted with a sample of 99 patients undergoing cardiac surgery, where the application of a cardiac rehabilitation program divides into seven stages (Winkelmann et al., 2015). The intensity progression along each stage was done individually in a set of low intensity exercises, starting at 2 met's and progressing to 4 met's at the last stage. It was possible to conclude, that the program developed by stages was important in the protocol orientation in phase I, showing the postoperative evolution until hospital discharge (Winkelmann et al., 2015).

In a self-controlled clinical trial conducted with a sample of 70 patients with coronary artery disease and left (mild to moderate) ventricular dysfunction, the impact of a cardiac rehabilitation program on exercise capacity, quality of life and functional status was determined (Sadeghi et al., 2015). This trial lasted for eight consecutive weeks and users were evaluated for sleep, walking, cycling, and other exercises. At the end of the program they found that the maximum exercise capacity increased (from 8 to 10 met's; $P<0.001$ ), such as quality of life and functional capacity (Sadeghi et al., 2015).

In addition to being well known, a reduction in blood pressure is also documented after 4 weeks of regular physical activity (Price et al., 2016). After analyzing the results, it can be concluded that supervised physical exercise allowed improvements in blood pressure and heart rate control but were not statistically significant.

Indeed, cardiac rehabilitation programs have evolved and gained ground in the prevention and treatment of heart disease, demonstrating effectiveness and contributing to the quality of life in today's society (Griffo et al., 2013). A study conducted on patients with heart failure, who underwent coronary artery bypass grafting, was evaluated the quality of life in the preoperative and postoperative periods, relating it to their age, anxiety and cardiac rehabilitation programme attendance (Barolia et al., 2012). After all the coronary artery bypass grafting recovery process, it is possible concluded that the quality of life of patients improved from prior to and 1 month after coronary artery bypass grafting while differing with respect to age, gender and cardiac rehabilitation programme attendance (Barolia et al., 2012).

A rehabilitation nursing care intervention project was designed, implemented and evaluated. The benefits achieved by the rehabil- 
itation nurse specialist intervention in these programs are evident and visible, that means, the optimization of cardio-respiratory capacity, the promotion of healthy lifestyle, and the consolidation of knowledge. Indeed, physical exercise is a robust measure in the evolution of physical and psychosocial well-being, functional capacity and general health, which are strong indicators of quality of life (Sadeghi et al., 2015). After the application of the rehabilitation nursing program, although only valid for the specific group of patients analyzed, it showed effectiveness and allowed significant gains in quality of life after coronary artery bypass grafting. It is of utmost importance to insist on health education, supervised exercise, early mobilization, breathing exercises during the preoperative and postoperative periods (during hospitalization) and positively influencing physical, social and mental function. Therefore, it is necessary to raise awareness about the fragility related to physical and mental health, inherent to the recovery process of the coronary artery bypass grafting user, in order to promote their independence.

\section{CONFLICT OF INTEREST}

No potential conflict of interest relevant to this article was reported.

\section{REFERENCES}

Achttien RJ, Staal JB, van der Voort S, Kemps HM, Koers H, Jongert MW, Hendriks Ej; Practice Recommendations Development Group. Exercise-based cardiac rehabilitation in patients with coronary heart disease: a practice guideline. Neth Heart J 2013;21:429-438.

Amorim H, Cadilha R, Parada F, Rocha A. Progression of aerobic exercise intensity in a cardiac rehabilitation program. Rev Port Cardiol 2019; 38:281-286.

Barolia R, Ali F, Jaffar S. Coronary artery bypass grafting: quality of life of patients in Karachi. Br J Nurs 2012;21:349-355.

Benjamin EJ, Virani SS, Callaway CW, Chamberlain AM, Chang AR, Cheng S, Chiuve SE, Cushman M, Delling FN, Deo R, de Ferranti SD, Ferguson JF, Fornage M, Gillespie C, Isasi CR, Jiménez MC, Jordan LC, Judd SE, Lackland D, Lichtman JH, Lisabeth L, Liu S, Longenecker CT, Lutsey PL, Mackey JS, Matchar DB, Matsushita K, Mussolino ME, Nasir K, O’Flaherty M, Palaniappan LP, Pandey A, Pandey DK, Reeves MJ, Ritchey MD, Rodriguez CJ, Roth GA, Rosamond WD, Sampson UKA, Satou GM, Shah SH, Spartano NL, Tirschwell DL, Tsao CW, Voeks JH, Willey JZ, Wilkins JT, Wu JH, Alger HM, Wong SS, Muntner P; American Heart Association Council on Epidemiology and Preven- tion Statistics Committee and Stroke Statistics Subcommittee. Heart disease and stroke statistics-2018 update: a report from the American Heart Association. Circulation 2018;137:e67-e492.

Borzou SR, Amiri S, Salavati M, Soltanian AR, Safarpoor G. Effects of the first phase of cardiac rehabilitation training on self-efficacy among patients undergoing coronary artery bypass graft surgery. J Tehran Heart Cent 2018;13:126-131.

Diab MS, Bilkhu R, Soppa G, Edsell M, Fletcher N, Heiberg J, Royse C, Jahangiri $\mathrm{M}$. The influence of prolonged intensive care stay on quality of life, recovery, and clinical outcomes following cardiac surgery: a prospective cohort study. J Thorac Cardiovasc Surg 2018;156:19061915.e3.

Griffo R, Ambrosetti M, Tramarin R, Fattirolli F, Temporelli PL, Vestri AR, De Feo S, Tavazzi L; ICAROS investigators. Effective secondary prevention through cardiac rehabilitation after coronary revascularization and predictors of poor adherence to lifestyle modification and medication. Results of the ICAROS Survey. Int J Cardiol 2013;167: 1390-1395.

Herdy AH, López-Jiménez F, Terzic CP, Milani M, Stein R, Carvalho T, Serra S, Araujo CG, Zeballos PC, Anchique CV, Burdiat G, González K, González G, Fernández R, Santibáñez C, Rodríguez-Escudero JP, Ilarraza-Lomelí H. South American guidelines for cardiovascular disease prevention and rehabilitation. Arq Bras Cardiol 2014;103(2 Suppl 1):1-31.

Hillis LD, Smith PK, Anderson JL, Bittl JA, Bridges CR, Byrne JG, Cigarroa JE, DiSesa VJ, Hiratzka LF, Hutter AM Jr, Jessen ME, Keeley EC, Lahey SJ, Lange RA, London MJ, Mack MJ, Patel MR, Puskas JD, Sabik JF, Selnes O, Shahian DM, Trost JC, Winniford MD, Jacobs AK, Anderson JL, Albert N, Creager MA, Ettinger SM, Guyton RA, Halperin JL, Hochman JS, Kushner FG, Ohman EM, Stevenson W, Yancy CW; American College of Cardiology Foundation/American Heart Association Task Force on Practice Guidelines. 2011 ACCF/AHA guideline for coronary artery bypass graft surgery: executive summary: a report of the American College of Cardiology Foundation/American Heart Association Task Force on Practice Guidelines. J Thorac Cardiovasc Surg 2012;143: $4-34$.

Kotseva K, Wood D, De Bacquer D, De Backer G, Rydén L, Jennings C, Gyberg V, Amouyel P, Bruthans J, Castro Conde A, Cífková R, Deckers JW, De Sutter J, Dilic M, Dolzhenko M, Erglis A, Fras Z, Gaita D, Gotcheva N, Goudevenos J, Heuschmann P, Laucevicius A, Lehto S, Lovic D, Miličić D, Moore D, Nicolaides E, Oganov R, Pajak A, Pogosova N, Reiner Z, Stagmo M, Störk S, Tokgözoğlu L, Vulic D; EUROASPIRE Investigators. EUROASPIRE IV: A European Society of Cardiology survey on the lifestyle, risk factor and therapeutic management of coronary patients from 24 European countries. Eur J Prev Cardiol 2016; 
23:636-648.

Mares MA, McNally S, Fernandez RS. Effectiveness of nurse-led cardiac rehabilitation programs following coronary artery bypass graft surgery: a systematic review. JBI Database System Rev Implement Rep 2018;16:2304-2329.

Piepoli MF, Hoes AW, Agewall S, Albus C, Brotons C, Catapano AL, Cooney MT, Corrà U, Cosyns B, Deaton C, Graham I, Hall MS, Hobbs FDR, Løchen ML, Löllgen H, Marques-Vidal P, Perk J, Prescott E, Redon J, Richter DJ, Sattar N, Smulders Y, Tiberi M, van der Worp HB, van Dis I, Verschuren WMM, Binno S; ESC Scientific Document Group. 2016 European Guidelines on cardiovascular disease prevention in clinical practice: The Sixth Joint Task Force of the European Society of Cardiology and Other Societies on Cardiovascular Disease Prevention in Clinical Practice (constituted by representatives of 10 societies and by invited experts) Developed with the special contribution of the European Association for Cardiovascular Prevention \& Rehabilitation (EACPR). Eur Heart J 2016;37:2315-2381.

Pinto R, Angarten V, Santos V, Melo X, Santa-Clara H. The effect of an expanded long-term periodization exercise training on physical fitness in patients with coronary artery disease: study protocol for a randomized controlled trial. Trials 2019;20:208.

Price KJ, Gordon BA, Bird SR, Benson AC. A review of guidelines for cardiac rehabilitation exercise programmes: is there an international consensus? Eur J Prev Cardiol 2016;23:1715-1733.

Riebe D, Franklin BA, Thompson PD, Garber CE, Whitfield GP, Magal M, Pescatello LS. Updating ACSM's Recommendations for exercise prepar- ticipation health screening. Med Sci Sports Exerc 2015;47:2473-2479.

Sadeghi M, Garakyaraghi M, Taghavi M, Khosravi M, Sarrafzadegan N, Roohafza $\mathrm{H}$. The impacts of cardiac rehabilitation program on exercise capacity, quality of life, and functional status of coronary artery disease patients with left ventricular dysfunction. Rehabil Nurs 2015; 40:305-309.

Sandesara PB, Lambert CT, Gordon NF, Fletcher GF, Franklin BA, Wenger NK, Sperling L. Cardiac rehabilitation and risk reduction: time to "rebrand and reinvigorate". J Am Coll Cardiol 2015;65:389-395.

Sawatzky JA, Kehler DS, Ready AE, Lerner N, Boreskie S, Lamont D, Luchik D, Arora RC, Duhamel TA. Prehabilitation program for elective coronary artery bypass graft surgery patients: a pilot randomized controlled study. Clin Rehabil 2014;28:648-657.

Thomas RJ, Balady G, Banka G, Beckie TM, Chiu J, Gokak S, Ho PM, Keteyian SJ, King M, Lui K, Pack Q, Sanderson BK, Wang TY. 2018 ACC/ AHA clinical performance and quality measures for cardiac rehabilitation: a report of the American College of Cardiology/American Heart Association Task Force on performance measures. J Am Coll Cardiol 2018;71:1814-1837.

Townsend N, Nichols M, Scarborough P, Rayner M. Cardiovascular disease in Europe - epidemiological update 2015. Eur Heart J 2015;36: 2696-2705.

Winkelmann ER, Dallazen F, Bronzatti AB, Lorenzoni JC, Windmöller P. Analysis of steps adapted protocol in cardiac rehabilitation in the hospital phase. Rev Bras Cir Cardiovasc 2015;30:40-48. 